\title{
Interação de polifenóis e proteínas e o efeito na digestibilidade proteica de feijão comum (Phaseolus vulgaris L.) cultivar Pérola
}

\author{
Polyphenol and protein interaction and the effect on protein digestibility \\ in common bean (Phaseolus vulgaris L.) cultivar Perola
}

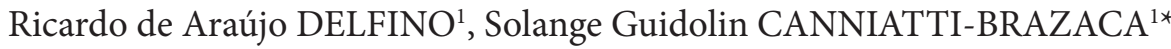

\section{Resumo}

O feijão é um alimento de importância na dieta dos brasileiros, sendo consumido com frequência. Além de sua importância proteica e de carboidratos contém também compostos bioativos que são essenciais para a manutenção da saúde dos indivíduos. Esses compostos podem se alterar com a estocagem e com a cocção, resultando em modificações de suas propriedades de ligação. A pesquisa teve por objetivos medir a capacidade de hidratação e o tempo de cocção antes e após o armazenamento e avaliar os teores de taninos em feijão comum, cultivar Pérola e a interferência desses compostos na digestibilidade de proteínas, estes parâmetros foram avaliados em feijões recém-colhidos e armazenados durante 3 e 6 meses, antes e após cocção. Para tanto, foram avaliados absorção de água, tempo de cocção em grãos de feijão antes e após armazenamento e composição centesimal dos grãos antes e após cocção. O teor de taninos diminuiu com a cocção e com o tempo de armazenamento; a digestibilidade aumentou com o tempo de armazenamento; a absorção de água diminuiu com o tempo de armazenamento; o tempo de cocção aumentou; e a composição centesimal apresentou diferença em relação à umidade e ao teor de fibra alimentar. Portanto foram obtidas alterações significativas para os parâmetros avaliados tanto para a cocção como para o tempo de armazenamento dos grãos de feijão comum, cultivar Pérola.

Palavras-chave: composição; cocção; hidratação; taninos; digestibilidade.

\begin{abstract}
Bean is one of the most important components of the Brazilian diet, and it is consumed frequently. It has been proven to be source of protein and carbohydrates and contains bioactive compounds that are essential for people's heath. These compounds can undergo changes as a result of storage and cooking leading to modifications in their bonding properties. The objectives of this research are to determine the common bean cultivar Perola's water absorption capacity and its cooking time before and after storage and to evaluate its content of tannin. The effect of these compounds on the protein digestibility of post-harvested beans and beans stored for 3 and 6 months at room temperature before and after cooking was also investigated. The water absorption capacity and cooking time were determined before and after storage of 3 and 6 months; the proximal composition of the grains was determined before and after cooking. The content of tannin decreased after cooking and with storage. The protein digestibility increased with storage. The water absorption capacity decreased with storage; the cooking time increased and the proximal composition of the grains presented difference in terms of moisture and content of alimentary fiber before and after cooking. Therefore, it can be said that significant changes in terms of cooking and storage occurred in the parameters of the common bean cultivar Perola grains evaluated.
\end{abstract}

Keywords: composition; cooking; water absorption; tannin; digestibility.

\section{Introdução}

O feijão é um alimento presente no prato dos brasileiros, tanto nos de renda mais elevada quanto nos de menor nível socioeconômico, servindo, inclusive, como uma das maiores fontes de proteína, quando consumido em conjunto com o arroz, em substituição às carnes, que têm maior custo. Além da importância proteica na dieta, o feijão contém compostos fenólicos, que possuem a capacidade antioxidante e, portanto, pode assumir papel relevante na diminuição do risco de doenças cardiovasculares, alguns tipos de câncer, Mal de Alzheimer e Parkinson (BUTTERFIELD et al., 2002). Entre os compostos fenólicos presentes no feijão, ocorrem os taninos que foram considerados tradicionalmente como antinutrientes pelos nutricionistas, por causa do efeito adverso na digestibilidade da proteína (BRAVO, 1998).

Segundo a FAO, o Brasil produziu em 2005, três milhões de toneladas numa área plantada de três milhões e oitocentos mil hectares, ou seja, uma média de $806 \mathrm{~kg} \cdot \mathrm{ha}^{-1}$. O consumo brasileiro foi de 16,62 kg/capita (FAOSTAT, 2007). Os taninos são encontrados em várias espécies de plantas incluindo os cereais e as leguminosas. Nas dietas para seres humanos e espécies de animais monogástricos, taninos podem reduzir a digestibilidade da proteína, carboidratos e minerais; diminuir a atividade de enzimas digestivas, além de causar danos à mucosa do intervalo digestivo ou exercer efeitos tóxicos sistêmicos (GOLANI; COCKELL; SEPEHR, 2005)

Recebido para publicação em 14/11/2007

Aceito para publicação em 9/3/2008 (002999)

'Departamento de Agroindústria, Alimentos e Nutrição, Escola Superior de Agricultura "Luiz de Queiroz", Universidade de São Paulo - USP, Piracicaba - SP, Brasil,

E-mail: sgcbraza@esalq.usp.br

* A quem a correspondência deve ser enviada 
Em geral, os taninos são classificados em hidrolisáveis e taninos condensados. Essa última classe é encontrada, geralmente, em plantas dicotiledôneas e em produtos alimentares; enquanto os hidrolisáveis são encontrados somente em quantidades traço. Ambos os tipos de taninos dietéticos exibem a habilidade em complexar e precipitar proteínas, consequentemente, ambos têm propriedades antinutricionais (GOLANI; COCKELL; SEPEHR, 2005).

Durante a estocagem dos grãos, ocorre a deterioração do produto em si, a qual é gradativa, irreversível e cumulativa. A velocidade de deterioração depende do ambiente, dos seus próprios componentes químicos e da condição física dos grãos no início do armazenamento. Essa perda de qualidade caracterizase por mudanças no sabor, escurecimento do tegumento dos grãos, em algumas cultivares, e aumento no grau de dureza dos grãos, o que resulta em acréscimos no tempo de cozimento (RIBEIRO et al., 2007).

O endurecimento dos grãos de feijão tem sido atribuído à ação de polifenóis, por meio de sua polimerização no tegumento ou pela lignificação dos cotilédones, ambos influenciando na capacidade de absorção de água dos grãos; o primeiro dificulta a penetração de água, e o segundo limita a capacidade de hidratação (MOURA, 1998).

A pesquisa teve por objetivos medir a capacidade de hidratação e o tempo de cocção antes e após o armazenamento e avaliar os teores de taninos em feijão comum, cultivar Pérola, e a interferência desses compostos na digestibilidade de proteínas. Estes parâmetros foram avaliados em feijões recém-colhidos e armazenados durante 3 e 6 meses, antes e após cocção.

\section{Material e métodos}

\subsection{Material}

Foram utilizados grãos de feijão comum cultivar Pérola, doados pela Empresa Brasileira de Pesquisa Agropecuária EMBRAPA, logo após a colheita. Os grãos recém-colhidos foram acondicionados em sacos de polietileno de $500 \mathrm{~g}$ e separados em 3 lotes. O primeiro lote já foi preparado para a realização das análises no tempo 0 (recém-colhido), os outros dois foram armazenados à temperatura ambiente por 3 e 6 meses, sendo analisados no final de cada período.

\section{Preparo das amostras}

Para realização das análises, com exceção do tempo de cocção e hidratação, as amostras foram trituradas em moinho de facas e peneiradas em malha de $0,5 \mathrm{~mm}$ com a finalidade de obtenção da farinha a ser utilizada para as análises. As análises foram realizadas logo após a moagem dos grãos. Para a cocção, o feijão foi lavado, deixado sob maceração por 12 horas e, posteriormente, cozido em autoclave por 10 minutos a $121^{\circ} \mathrm{C}$, conforme metodologia sugerida por Molina, Fuente e Bressani (1975). Para a maceração, foi utilizada a proporção feijão: água de 1:3 e, para a cocção 1:2 para as análises que necessitaram de amostras secas, foi realizada secagem parcial em estufa de circulação de ar forçada a $55-60^{\circ} \mathrm{C}$, posterior armazenamento em sacos de polietileno a $4{ }^{\circ} \mathrm{C}$, sendo os grãos moídos no momento em que as análises iriam ser realizadas.

\subsection{Análises químicas}

\section{Composição centesimal}

Com a finalidade de caracterizar quimicamente as amostras, foi realizada a análise de sua composição centesimal. Para tanto, foram determinados o teor de umidade, proteína bruta, extrato etéreo, fibra alimentar, carboidratos disponíveis e cinza, de acordo com a metodologia indicada pela AOAC (2006).

\section{Taninos}

Os taninos foram analisados segundo metodologia descrita por Price, Hagerman e Buther (1980), através de extração com metanol e posterior reação colorimétrica com solução de vanilina e leitura a $500 \mathrm{~nm}$ em espectrofotômetro, obtendo-se assim a concentração de taninos a partir de uma curva padrão de catequina, sendo os resultados expressos em \%mEq de catequina.

\section{Digestibilidade da proteína}

A digestibilidade in vitro foi determinada segundo metodologia descrita por Akeson e Stahmann (1964). A metodologia utiliza solução ácida de pepsina e solução básica de pancreatina para promover a digestão e os resultados expressos em porcentagem de proteína digerida.

\subsection{Análises físicas}

\section{Absorção de água}

O tempo de hidratação dos grãos foi determinado à temperatura ambiente com $10 \mathrm{~g}$ de grãos para $50 \mathrm{~mL}$ de água destilada, com intervalos de medidas de $1 \mathrm{em} 1$ hora, até que a leitura estabilizasse por três vezes consecutivas (MORRIS; OLSON; BEAN, 1950).

\section{Tempo de cocção}

Os mesmos grãos utilizados para análise do tempo de hidratação foram utilizados para medir o tempo de cocção, cujo equipamento de medição denomina-se cocção de Mattson, conforme o proposto por Burr, Kon e Morris (1968). O tempo ótimo de cocção foi definido como o tempo necessário para que 13 hastes perfurassem os grãos.

\subsection{Análise estatística}

O delineamento experimental foi o totalmente ao acaso com 3 repetições, sendo todas as análises realizadas em triplicata. Foram feitas comparações das médias entre os tratamentos e regressão polinomial para o fator tempo. Foi realizada a análise de variância, Teste $\mathrm{F}$ e, posteriormente, teste de Tukey, quando o teste $\mathrm{F}$ foi significativo em nível de $5 \%$. Foi utilizado o programa estatístico SAS (1996). 


\section{Resultados e discussão}

\subsection{Composição centesimal}

Os resultados obtidos da composição centesimal são apresentados na Tabela 1.

A composição centesimal encontrada destaca a importância do feijão comum quanto à quantidade de proteínas, minerais e carboidratos, mostrando valores similares aos apresentados na Tabela Brasileira de Composição de Alimentos - TBCA(USP, 2007). Os feijões antes e após cocção não diferiram significativamente quando os dados são comparados em base seca, com exceção da fibra alimentar que apresenta variação com a cocção, pois ocorre quebra de suas cadeias.

\section{Taninos}

Os valores observados na Tabela 2 são similares aos de Mechi, Canniatti-Brazaca e Arthur (2005), que encontraram $0,93 \% \mathrm{mEq}$ de catequina em feijão preto sem armazenamento.

Oliveira et al. (2001) estudaram o efeito do processamento doméstico no feijão comum incluindo maceração prévia à cocção com descarte da água de maceração não absorvida pelos grãos. Constataram que esse processo resulta em redução de $85 \%$ nos fatores antinutricionais, entre eles os taninos. Isso se dá porque grande parte dos taninos é transportada por lixiviação à água de maceração, como pode ser observado pelos valores obtidos após cocção dos grãos (Tabela 2).

A quantidade de taninos no grão recém-colhido é maior do que após 3 e 6 meses de armazenamento. Essa diminuição no teor de taninos provavelmente ocorreu devida à oxidação e à menor solubilidade, decorrentes de seu maior grau de polimerização. Os polifenóis ligados a outros componentes celulares são mais difíceis de serem extraídos, ocorre modificação de suas estruturas e dos componentes a eles ligados, fazendo com que o teor extraído seja menor após períodos de armazenamento dos grãos (RIOS, 2000).

Essas alterações que acontecem nos taninos contribuem para alterações físicas nos grãos. As altas temperaturas e as condições de umidade relativa alta fazem com que os taninos migrem da casca para a parede do cotilédone e lamela média, provocando grãos hard to cook. Além disso, a oxidação dos taninos na casca pode restringir a mobilidade da água e então contribuir para as condições hard shell em sementes de leguminosas estocadas (STANLEY, 1992).

\section{Digestibilidade}

Os valores de digestibilidade proteica in vitro (Tabela 3 ) foram próximos aos obtidos por Mechi, Canniatti-Brazaca e Arthur (2005) que encontraram $83,96 \%$ para amostra crua e $84,20 \%$ para a cozida.

Bressani, Hernandez e Braham (1988) sugerem dois mecanismos que poderiam explicar o efeito de polifenóis na redução da digestibilidade proteica: reação entre proteínas e fenóis durante o processamento de feijão e/ou entre fenóis e enzimas do trato digestivo. Ainda demonstraram que a influência da con-
Tabela 1. Composição centesimal (\% base seca) do feijão comum cultivar Pérola antes e após cocção.

\begin{tabular}{lrr}
\hline \multicolumn{1}{c}{$\%$} & \multicolumn{1}{c}{ Feijão cru } & Feijão cozido \\
\hline Umidade & $13,07 \pm 0,00^{1 \mathrm{~b} 2}$ & $80,79 \pm 0,00^{\mathrm{a}}$ \\
Cinza & $4,65 \pm 0,00^{\mathrm{a}}$ & $4,09 \pm 0,00^{\mathrm{a}}$ \\
Proteína & $24,96 \pm 0,01^{\mathrm{a}}$ & $25,77 \pm 0,00^{\mathrm{a}}$ \\
Extrato etéreo & $1,78 \pm 0,00^{\mathrm{a}}$ & $1,95 \pm 0,00^{\mathrm{a}}$ \\
Carboidratos totais & $68,61 \pm 0,00^{\mathrm{a}}$ & $68,19 \pm 0,00^{\mathrm{a}}$ \\
Fibra alimentar & $21,94 \pm 0,00^{\mathrm{a}}$ & $11,90 \pm 0,01^{\mathrm{b}}$ \\
\hline
\end{tabular}

${ }^{1}$ Média de três repetições \pm desvio padrão; ${ }^{2}$ Letras diferentes na horizontal diferem significativamente $(\mathrm{p} \leq 0,05)$.

Tabela 2. Teor de Taninos \%mEq de catequina (matéria seca) em feijão cru e cozido, em diferentes tempos de armazenamento.

\begin{tabular}{cccc}
\hline & Recém-colhido & Armazenado 3 meses & Armazenado 6 meses \\
\hline Cru & $1,13^{1} \pm 0,00^{\mathrm{a} 2 \mathrm{~A} 3}$ & $1,10 \pm 0,00^{\mathrm{aA}}$ & $0,90 \pm 0,00^{\mathrm{bA}}$ \\
Cozido & $0,74 \pm 0,00^{\mathrm{aB}}$ & $0,62 \pm 0,00^{\mathrm{bB}}$ & $0,23 \pm 0,00^{\mathrm{BB}}$ \\
\hline
\end{tabular}

${ }^{1}$ Média de três repetições \pm desvio padrão; ${ }^{2}$ Médias com letras maiúscula(s) diferente(s) na vertical diferem significativamente $(\mathrm{p} \leq 0,05) ;{ }^{3}$ Médias com letras minúscula(s) diferente(s) na horizontal diferem significativamente $(\mathrm{p} \leq 0,05)$.

Tabela 3. Digestibilidade proteica in vitro \% (matéria seca) em feijão cru e cozido, em diferentes tempos de armazenamento.

\begin{tabular}{lccc}
\hline & Recém-colhido & Armazenado 3 meses & Armazenado 6 meses \\
\hline Cru & $92,80^{1} \pm 0,00^{\mathrm{a} 2 \mathrm{A3}}$ & $93,36 \pm 0,00^{\mathrm{bA}}$ & $95,93 \pm 0,00^{\mathrm{abA}}$ \\
Cozido & $92,27 \pm 0,00^{\mathrm{aA}}$ & $93,13 \pm 0,00^{\mathrm{bB}}$ & $97,86 \pm 0,00^{\mathrm{cB}}$ \\
\hline
\end{tabular}

${ }^{1}$ Média de três repetições \pm desvio padrão; ${ }^{2}$ Médias com letras maiúscula(s) diferente(s) na vertical diferem significativamente ( $\mathrm{p} \leq 0,05) ;{ }^{3}$ Médias com letras minúscula(s) diferente(s) na horizontal diferem significativamente $(\mathrm{p} \leq 0,05)$.

centração de taninos na digestibilidade da proteína e qualidade do feijão se expressa pela correlação negativa entre a digestibilidade in vitro e o teor de taninos presentes no produto.

$\mathrm{O}$ aumento da digestibilidade nas amostras cozidas provavelmente se dá pela eliminação de fatores antinutricionais, cuja complexação com as proteínas impede a ação das enzimas proteolíticas. Ocorrem também, com a cocção, alterações estruturais das proteínas, provocando o aumentando da susceptibilidade à hidrólise enzimática (CARBONARO; MARLETTA; CARNOIVALE, 1992).

\section{Absorção de água}

A capacidade de absorção de água (Tabela 4) está relacionada com a qualidade do grão. Os grãos que absorvem mais água tendem a ser os de mais fácil cocção, sendo essa característica muito importante para sua comercialização.

Esses valores (Tabela 4) condizem com os encontrados por Rios, Abreu e Correa (2003), que estudaram os efeitos da estocagem sobre a capacidade de hidratação, em temperatura ambiente, durante oito meses, e encontraram diminuição na capacidade de absorção de água com o armazenamento. $\mathrm{Na}$ variedade ESAL 550, por exemplo, os valores foram reduzidos de 122,35 para $117,61 \%$ durante o armazenamento. Rodrigues et al. (2005) estudaram apenas a capacidade de absorção de água, independente do tempo de armazenamento e encontraram valores entre 90,24 e 113,06\%, enquanto Esteves et al. (2002) 
Tabela 4. Capacidade de Absorção de Água (\%) do feijão em diferentes tempos de armazenamento.

\begin{tabular}{cccc}
\hline Capacidade de absorção de água do feijão cru & \multicolumn{3}{c}{ Cultivar do feijão e tempo de armazenamento } \\
\cline { 2 - 4 } & Recém-colhido & Armazenado 3 meses & Armazenado 6 meses \\
\hline Porcentagem & $130^{1} \pm 0^{\mathrm{a} 2}$ & $107 \pm 0^{\mathrm{b}}$ & $110 \pm 0^{\mathrm{b}}$ \\
mL absorvidos por 10 g de grãos & $13 \pm 0^{\mathrm{a}}$ & $11 \pm 0^{\mathrm{b}}$ & $11 \pm 0^{\mathrm{b}}$ \\
Tempo médio de estabilização (horas) & 7,0 & 3,6 & 4,0 \\
\hline
\end{tabular}

${ }^{1}$ Média de três repetições \pm desvio padrão; ${ }^{2}$ Médias com letra(s) minúscula(s) diferente(s) na horizontal difere(m) significativamente $(\mathrm{p} \leq 0,05)$.

compararam seis linhagens de feijão e obtiveram valores entre 119,60 e $169,14 \%$.

Segundo Rios, Abreu e Correa (2003), a taxa de embebição é influenciada pelo tipo de feijão, nível de umidade, idade, entre outros fatores. Além disso, a oxidação de taninos no tegumento da semente pode restringir a mobilidade de água e então contribuir para a condição de hard shell durante o armazenamento, reduzindo a capacidade de absorção, como foi observado nos tempos de 3 e 6 meses de armazenamento (Tabela 4).

\section{Tempo médio de cocção}

Na Figura 1 são apresentados os tempos de cocção para os diferentes tempos de armazenamento dos grãos de feijão comum, cultivar Pérola.

Lemos et al. (2004) estudaram vinte e nove genótipos de feijão recém-colhido e encontraram valores variando entre $15 \mathrm{e}$ 25 minutos. Rodrigues et al. (2005), avaliando amostras recémcolhidas, encontraram valores entre 15,24 e 20,38 minutos. Carbonell, Carvalho e Pereira (2003) usaram feijões armazenados em freezer doméstico $\left(-18{ }^{\circ} \mathrm{C}\right)$, por até 60 dias após a colheita, e encontraram valores entre 10,5 e 103 minutos. $\mathrm{O}$ genótipo e as condições de cultivo, incluindo as condições climáticas, são fatores importantes na determinação do tempo de cocção (CARBONELL; CARVALHO; PEREIRA, 2003; LEMOS et al., 2004).

Assim como a capacidade de hidratação, o tempo de cocção se estabiliza após os três meses de armazenamento, isso já é esperado pelo fato de essas duas propriedades apresentarem uma relação inversa, ou seja, quanto maior a capacidade de hidratação dos grãos, menor é o tempo necessário para a cocção. Segundo Scholz e Fonseca Júnior (1999 a, b), o cozimento dos grãos de feijão depende da capacidade de absorção de água e das características do tegumento do grão, bem como a qualidade tecnológica depende da qualidade do grão de feijão no momento da colheita e das técnicas de processamento.

Para Garcia et al. (1998), os feijões HTC (hard to cook) apresentaram quantidades mais elevadas de pectatos e três vezes mais ácido ferúlico, que é um composto fenólico, ligados à fração péctica solúvel. A presença de compostos fenólicos ligados à pectina solúvel nos feijões HTC causam mudanças na aderência das células, inibindo desse modo sua separação, quando os feijões passam pelo processo de cocção, e assim impedindo o amolecimento do grão. Essas alterações resultam em maior tempo de cocção dos grãos, como apresentado na Figura 1.
Tempo de cocção feijão Pérola
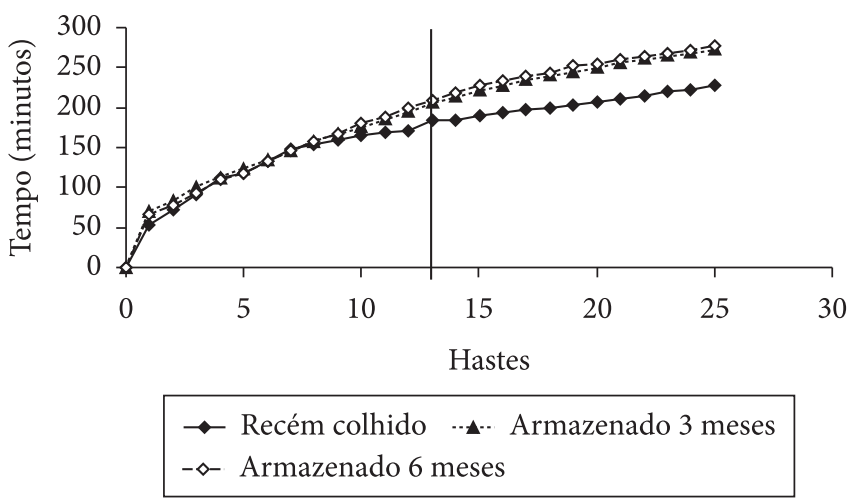

Figura 1. Tempo de cocção do feijão Carioca Pérola em diferentes tempos de armazenamento.

\section{Conclusões}

A cocção diminui o teor de fibras alimentares nos grãos de feijão comum, cultivar Pérola.

O teor de taninos diminui com o tempo de armazenamento e com a cocção, o que pode ser um fator para o aumento da digestibilidade com o tempo de armazenamento, de três para seis meses.

A capacidade de absorção de água e o tempo de cocção, cuja relação é inversamente proporcional, se estabilizaram a partir dos três meses de armazenamento.

\section{Agradecimentos}

À EMBRAPA pela doação dos grãos sem os quais a realização dessa pesquisa seria inviável e ao CNPq pela bolsa de iniciação científica.

\section{Referências bibliográficas}

AKESON, W. R.; STALMANN, M. A. A pepsina pancreatina digest index of protein quality evaluation. Journal of Nutrition, v. 83, n. 3, p. 257-261, 1964.

ASSOCIATION OF OFFICIAL ANALYTICAL CHEMISTS - AOAC. Official methods of analysis. Washington, 1995.

BRAVO, L. Polyphenols: chemistry, dietary sources, metabolism and nutrition significance. Nutrition Reviews, v. 56, n. 11, p. 317-333, 1998.

BRESSANI, R.; HERNANDEZ, E.; BRAHAM, E. Relationship between content and intake of bean polphenolics and protein digestibility 
in humans. Plant Foods for Human Nutrition, v. 38, n. 1, p. 5-21, 1988.

BURR, H. R.; KON, S.; MORRIS, H. J. Cooking rates of dry beans as influenced by moisture content and temperature and time of storage. Food Technology, v. 22, n. 10, p. 336-338, 1968.

BUTTERFIELD, D. et al. Nutritional approaches to combat oxidative stress in Alzheimer's disease. The Journal of Nutritional Biochemistry, v. 13, n. 8, p. 444-461, 2002.

CARBONARO, M.; MARLETTA, L.; CARNOVALLE, E. Factors affecting cysteine reactivity in proteolytic digests of Phaseolus vulgaris. Journal of Agricultural and Food Chemistry, v. 40, n. 2, p. 169-173, 1992.

CARbonell, S. A. M.; CARVAlho, C. R. L.; PEREIRA, V. R. Qualidade tecnológica de grãos de genótipos de feijoeiro cultivados em diferentes ambientes. Bragantia, v. 62, n. 3, p. 369-379, 2003.

FOOD AND AGRICULTURE ORGANIZATION OF THE UNITED NATIONS - FAOSTAT. Disponível em: <http://faostat.fao.org/ site/609/default.aspx\#ancor>. Acesso em: 25 jan. 2007.

GARCIA, E. et al. Hard-to-Cook Beans (Phaseolus vulgaris): involvement of Phenolic Compounds and Pectates. Journal of Agricultural and Food Chemistry, v. 46, n. 6, p. 2110-2116, 1998.

GOLANI, G. S.; COCKELL, K. C.; SEPEHR, E. Effects of antinutritional factors on protein digestibility and amino acid availability in foods. Journal of AOAC International, v. 88, n. 3, p. 967-987, 2005.

LEMOS, L. B. et al. Características agronômicas e tecnológicas de genótipos de feijão do grupo comercial Carioca. Pesquisa Agropecuária Brasileira, v. 39, n. 4, p. 319-326, 2004.

MECHI, R.; CANIATTI-BRAZACA, S. G.; ARTHUR, V. Avaliação química, nutricional e fatores antinutricionais do feijão preto (Phaseolus vulgaris L.) irradiado. Ciência e Tecnologia de Alimentos, v. 25, n. 1, p. 109-114, 2005.

MOLINA, M. R.; FUENTE, G.; BRESSANI, R. Interrelationships between storage, soaking time, cooking time, nutritive value and other characteristics of the black bean (Phaseolus vulgaris ). Journal of Food Science, v. 40, n. 3, p. 587-591, 1975.

MOURA, A. C. C. Análises físico-químicas e enzimáticas antes e após armazenamento em grãos de feijão (Phaseolus vulgaris L.) submetidos a diferentes tempos e tipos de secagem. 1998. $70 \mathrm{f}$. Dissertação (Mestrado em Ciência dos Alimentos) - Universidade Federal de Lavras, Lavras, 1998.
MORRIS, H. J.; OLSON, R. L.; BEAN, R. C. Processing quality of varieties and strains of dry beans. Food Technology, v. 4, n. 7, p. 247-251, 1950.

OLIVEIRA, A. C. et al. O processamento doméstico do feijão-comum ocasionou uma redução nos fatores antinutricionais fitatos e taninos, no teor de amido e em fatores de flatulência rafinose, estaquiose e verbascose. Archivos Latinoamericanos de Nutrition, v. 51, n. 3, p. 276-283, 2001.

PRICE, M. L.; HAGERMAN, A. E.; BUTHER, L. G. Tannin content of cowpeas, chickpeas, pigeonpeas and mung beans. Journal of Agricultural and Food Chemistry, v. 28, n. 2, p. 459-461, 1980.

RIBEIRO, N. D. et al. Efeito de períodos de semeadura e das condições de armazenamento sobre a qualidade de grãos de feijão para o cozimento. Bragantia, v. 66, n. 1, p. 157-163, 2007.

RIOS, A. O. Avaliação da época de colheita e do armazenamento no escurecimento e digestibilidade de três cultivares de feijão (Phaseolus vulgaris, L.). 2000.59 f. Dissertação (Mestrado em Ciências dos Alimentos) - Universidade Federal de Lavras, Lavras, 2000.

RIOS, A. O.; ABREU, C. M. P.; CORREA, A. D. Efeito da estocagem e das condições de colheita sobre algumas propriedades físicas, químicas e nutricionais de três cultivares de feijão (Phaseolus vulgaris, L.). Ciência e Tecnologia de Alimentos, v. 23, supl., p. 39-45, 2003.

RODRIGUES, J. A. et al. Qualidade para o cozimento de grãos de feijão obtidos em diferentes épocas de semeadura. Bragantia, v. 64, n. 3, p. 369-376, 2005.

SCHOLZ, M. B. S.; FONSECA JUNIOR, N. S. Efeitos de ambiente, dos genótipos e da interação genótipos $\mathrm{x}$ ambiente na qualidade tecnológica do feijão do grupo cores no Estado do Paraná. In: REUNIÃO NACIONAL DE PESQUISA DE FEIJÃO, 6, 1999, Salvador. Resumos expandidos... Goiânia: EMBRAPA Arroz e Feijão, 1999a. p. 339-342. (v. 1)

SCHOLZ, M. B. S.; Fonseca Junior, N. S. Influência ambiental, genotípica e sua interação na qualidade tecnológica do feijão do grupo preto no Paraná.. In: REUNIÃO NACIONAL DE PESQUISA DE FEIJÃO, 6, 1999, Salvador. Resumos expandidos... Goiânia: EMBRAPA Arroz e Feijão, 1999b. p. 389-392. (v. 1)

STANLEY, D. W. A possible role for condensed tannins in bean hardening. Food Research International, v. 25, n. 3, p. 187-192, 1992.

STATISTICAL ANALYSIS SYSTEM INSTITUTE - SAS. Sas/Qc software: usage and reference. Version 6. 2 ed. Cary, 1996. (2 v.)

UNIVERSIDADE DE SÃO PAULO - USP. Tabela Brasileira de Composição de Alimentos: TBCA. São Paulo, 2007. Disponível em: $<$ http://www.fcf.usp.br/tabela/index.asp >. Acesso em: 18 out. 2007. 